\title{
Inquiry in Plato's Meno \\ What Are We Supposed to Learn From the Experiment with the Slave Boy?
}

\section{Larry J. Waggle}

Illinois State University

Plato's Meno as long been supposed to be one of Plato's transitional dialogues. Trying to understand the Meno in this way, however, gives rise to a number of problems, not the least of which is that positions or arguments from other dialogues are often used to interpret the Meno. ${ }^{1}$ In this paper, I propose to interpret one of the more puzzling parts of the Meno by containing my reading to just this dialogue and not importing views from other dialogues. In the Meno, Plato presents and uses the so-called doctrine of recollection to overcome a paradox introduced by the character Meno. Interpretations of this dialogue typically have a problem explaining the connection between the paradox, the use of the doctrine of recollection and the subsequent experiment with the slave boy. Some have argued that the doctrine of recollection is Plato's initial attempt at presenting his epistemological views.' Others have argued that the doctrine of recollection is the initial departure by Plato from the Socratic elenchus. ${ }^{3}$ Although I shall not address these arguments explicitly, my contention is that these interpretations do not address the specific problem, introduced in this dialogue, concerning the purpose of inquiry. I shall argue that Plato's use of the doctrine of recollection with respect to the experiment with the slave boy serves an explanatory function. More precisely, I shall argue that this doctrine demonstrates how new beliefs are formed and how inquiry can be guided by these beliefs. ${ }^{4}$

Before delving in too far, there are at least four reasons we should be suspicious of the traditional understanding of the doctrine of recollection found in the Meno. First, Socrates' retraction is typically overlooked and not taken into consideration. I think this is vitally important, because Plato is telling us that there is more going on in this section than meets the eye. If we fail to take account 
of this retraction, then we may be missing the point of this whole section of the dialogue. Also, if Plato is retracting some of this presentation, then this presupposes that he is aware that there are certain fundamental problems that he cannot address. Second, these problems in this doctrine that are not specifically addressed are, first of all, how does the soul know things in the first place. If successive reincarnations of the soul account for the knowledge that is present in the soul, then there should be some difference between the soul's first incarnation and all successive incarnations. If not, then what explanatory role does the soul's numerous incarnations play in the account offered. If it is the case that the soul is immortal, and has been born many times and, on that basis, has experienced all things both here and in the underworld, there should be a difference in the knowledge possessed by a soul on the first incarnation and that of a soul on its $n^{\text {th }}$ incarnation. Since the soul, first time around, would only know those things in the underworld, or, conversely, only those things experienced of this world, and the soul on its, say, $20^{\text {th }}$ time around would have experienced things both here and yonder, there should be a marked difference between the amount of knowledge held by these souls or the speed in which they recollect. If there isn't, then what difference is there between the first incarnation of a soul with respect to the amount of knowledge it contains and the twentieth incarnation? If each successive incarnation does not affect the overall amount of knowledge or access the soul has to this knowledge, then why introduce this notion into the presentation of the doctrine? There does not seem to be any indication, in the Meno, that each successive incarnation does anything either beneficial or detrimental to the soul with respect to its condition and access to knowledge. The first incarnation soul is in the same condition, with respect to starting points, as the twentieth incarnation soul. It also does not appear that the number of incarnations of the soul play any role whatsoever in the identification of objects in the world. Both the first incarnation soul and the twentieth incarnation soul are still subject to the need for dialectic and philosophical inquiry.

Third, even if the doctrine of recollection is taken to be a theory of knowledge, it does not explain how we acquire knowledge in 
the first place. That is, if the successive incarnations of the soul explain why a soul has knowledge, how does the soul acquire it in the first place? It would seem that upon the initial incarnation, the soul would only have experience of those things in the underworld. Notice that the presentation of this doctrine does not say that the soul has experience of some Platonic heaven with the Forms per $s e$. In fact, this dialogue does not even seem to suggest that the theory of forms has been formulated, yet, by Plato. All Socrates says is that the soul has experience of things both in this world and in the underworld. On the first time around, so to speak, the soul would only have experience of those things, whatever they are, in the underworld. So, how does the soul initially acquire any knowledge at all? Finally, how do we graft the slave boy case onto the doctrine of recollection? It does not seem as if he is reaching into his pre-natal experiences to extract knowledge, but rather that he is learning how to answer Socrates' questions. There remains a disconnect between the account of the doctrine of recollection and the experiment with the slave boy that remains puzzling even in the face of Socrates' careful attempt to join the two together. On these grounds, we have reason to be suspicious of the traditional reading of the doctrine of recollection.

In order to grapple with these difficulties, I shall, in brief, address the initial section of the dialogue, and the particular problem presented by the so-called Meno's paradox. I shall then address Socrates' presentation of the doctrine of recollection, and identify what I call the strong ${ }^{5}$ and weak versions of it. Next, I shall carefully address the experiment with the slave boy and provide a reading of this experiment that makes sense of some otherwise very puzzling passages within the experiment. I shall argue that these previous interpretations do not explain why, at the end of the experiment Socrates makes a retraction. In light of this retraction, I shall argue that we are justified in attributing only the weaker version of the doctrine of recollection to Plato in this dialogue. Any attempt to attribute a stronger interpretation of this doctrine must explain Socrates' retraction. And, as we shall see, I think the prospect of doing this is thin. The main problem introduced by Socrates' retraction concerns its scopc. What I mean by this is that, since Socrates does not insist that his argument is 
right in all other respects, what parts of the previous argument is rejected by this statement?

In the initial portion of the dialogue, Meno asks Socrates whether virtue can be taught, or if it is not teachable, the result of practice, or if it is neither of these, but something that men possess by nature or does virtue come to men by some other way. ${ }^{6}$ Socrates insists that if he does not know what something is, he could not know what qualities the thing possesses. ${ }^{7}$ It is important to note that throughout this dialogue, Socrates does not abandon this position. He says essentially the same thing at lines $86 \mathrm{~d}$, "we would not have investigated whether virtue is teachable or not before we had investigated what virtue itself is. . . . So, we must, it appears, inquire into the qualities of something the nature of which we do not yet know." Again, at the end of the dialogue, Socrates says, "We shall have clear knowledge of this when, before we investigate how it comes to be present in men, we first try to find out what virtue in itself is." (Line 100b). In order to understand why the paradox is introduced in the first place, we must understand the nature of the inquiry taking place in the dialogue. Meno wants an answer to his initial question concerning the manner in which we acquire virtue. ${ }^{8}$ Essentially, this question requires an understanding of the nature of virtue. The interpretive problem, then, becomes one of understanding how to inquire into the nature of something the knowledge of which the inquirers do not possess.

In order to discover an answer to this initial question, Socrates asks Meno to tell him what virtue is. We are led through four successive definitions. Each of which either contains the term to be defined in the definition, or the definition does not take the entire subject matter into consideration. These definitions are: 1 . There is a virtue for every action and every age, for every task of ours and every one of us, and the same is true for wickedness. (line72a); 2. Virtue is the ability to rule over men. (line 73d); 3 . Virtue is the desire for beautiful things and the power to acquire them. (line $77 \mathrm{~b}$ ); and 4 . To act in whatever you do with a part of virtue is virtue. (line 79c). Socrates rejects each of these definitions in turn, and demonstrates their deficiencies. But, a careful examination of these arguments is not the point of this paper. Instead, I would like to draw attention to the assistance Socrates 
provides Meno just after he undermines Meno's attempted definitions.

After each definition and counter argument, Socrates offers Meno some suggestions concerning how to better understand what Socrates is looking for. For example, the example of the swarm of bees and the analogy to Meno's initial definition of virtue demonstrates that Socrates is looking for the eidos in virtue of which all virtues are virtues. The definitions of shape and color that Socrates offers Meno as examples of the sort of definition he is looking for demonstrate another aspect of how Socrates understands inquiry. Socrates' comparison between the clever and disputatious debaters and those who are friends illustrate this difference. The clever, disputatious and contentious sort of debater would demand refutation before abandoning a view or position. In contrast, the friend of discussion offers answers that are not only true but in terms admittedly known to the questioner.

It is worth noting that one difference between Socrates second definition of shape, 9 shape is that which limits a solid (line 76b), and Socrates definition of color, an effluvium from shapes which fits the sight and is perceived (line 76d), which reflects another aspect of answering in terms that are not only true but in terms admittedly known to the questioner. That is, in the second definition of shape Socrates carefully explains to Meno each of the central terms of the definition (limit, and solid), and constructs the definition on the basis of Meno's admitted understanding of these terms only after they have been clearly defined. Just before the definition of color, Socrates asks Meno whether he would like him to answer in the manner of Gorgias (line 76c), and only focuses on Gorgias' acceptance of Empedocles' notion of effluvia. Socrates draws off of this notion that there are channels through which some effluvia fit and others that are either too big or too small. The notion of sight is mentioned but not elaborated. From these notions the theatrical (tragike) definition of color is constructed.

What I find important here is that, in the second definition of shape, Socrates himself offers his understanding of the terms included in the definition. With the definition of color, there is no indication, in the dialogue, that Socrates himself agrees with or even understands these notions from Gorgias, Empedocles, or 
Pindar. What thesc concessions from Meno do, in fact, demonstrate is that Meno understands poetic or metaphoric notions. This concession is quickly picked up by Socrates when he compares the definition of shape to that of color. Right at the end of line 76e, Socrates states that Meno would agree with him that the definition of shape is better than the definition of color, "if you (Meno) did not have to go away before the mysteries as you told me yesterday, but could remain and be initiated." ${ }^{10}$ Meno follows Socrates' lead and uses poetic language in constructing his third definition. The allusion to the mysteries is taken up later in the dialogue at the point where Plato introduces us to the doctrine of recollection.

The series of definitions and refutations comes to an abrupt end around line 80a. Meno, having tired of Socrates insistence that one cannot know the qualities of a thing without knowledge of that thing, accuses Socrates of casting a spell or using witchcraft on him. The Greek here is instructive. Kai nun, hos ge moi dokeis, goeteueis me kai pharmatteis kai atechnos katepadeis, hoste meston aporias gegonenai. (line 80a). And now, as it seems to me, you are beguiling me and bewitching me and subduing me with charms, so that I am completely at a loss. (trans. mine). At the end of Meno's speech, he warns Socrates not to travel because if Socrates were to behave like this as a stranger in another city, he would be driven away for practicing witchcraft. (line 80b). The last clause of this passage rather effectively clarifies Meno's charge against Socrates here. The Greek is hos goes apachtheies. The goes referred to here is one who howls out enchantments, or a sorcerer. Meno's inability to accurately define the nature of virtue is the result of Socrates' howling. Rather than assisting Meno to see the problems inherent in his conception of virtue, Meno claims that Socrates has howled some enchantment and numbed him into inactivity. Meno's sense of unsureness stems from the investigation and the frustration of searching for something using an unknown method.

However, in place of an admission of ignorance, Meno challenges Socrates. Meno presents the paradox which bears his name. Socrates refers to this paradox as eristikon logon, a debater's argument. The Greek here echos the division between those who are clever, disputatious debaters and those who are friends of investigation seen at line $75 \mathrm{c}$. Meno has allied himself with the 
former. The paradox is formulated is two ways, once by Meno and once by Socrates. Meno's formulation is "how will you look for it, Socrates, when you do not know at all what it is? How will you aim your search for something you do not know at all? If you should meet with it, how will you know that this is the thing that you did not know?" (Line 80e).

Socrates reformulation of this paradox is "a man cannot search either for what he knows or for what he does not know. He cannot search for what he knows-since he knows it, there is no need to search-nor for what he does not know, for he does not know what to look for?" (Line 81a). There is a subtle difference between these formulations," but that difference should not trouble us here. The upshot of the paradox is that investigation is pointless.

Rather than directly undermining Meno's contentious argument, Socrates takes a different route. Socrates tells Meno a story about a mystery concerning the soul.

As the soul is immortal, has been born often and has seen all things here and in the underworld, there is nothing which it has not learned; so it is in no way surprising that it can recollect the things it knew before, both about virtue and other things. As the whole of nature is akin, and the soul has learned everything, nothing prevents a man, after recalling one thing only-a process men call learning discovering everything else for himself, if he is brave and does not tire of the search, for searching and learning are, as a whole, recollection. (Line $81 \mathrm{c}-\mathrm{d}$ )

We can understand this claim in two ways. Let's call these two interpretations the strong and the weak interpretation. What makes the strong interpretation "strong" is that this interpretation attempts to take into consideration the metaphysical implications of the myth in conjunction with later Platonic notions. The weaker interpretation focuses on the work the myth performs in the course of the dialogue. What is important here is that in the weaker interpretation, these metaphysical notions do not play any role. The strong interpretation is that, in fact, the soul is immortal and contains within it all knowledge. Through a careful process of investigation, one can extract or recall this knowledge from the 
soul. The weaker interpretation rests on the rest of the passage.

We must, therefore, not believe the debater's argument, for it would make us idle, and fainthearted men like to hear it, whereas my argument makes them energetic and keen on the search. 1 trust this is true, and I want to inquire along with you into the nature of virtue. (line 81 e).

The weak claim is that there is something besides knowledge that can guide inquiry. This weaker interpretation may not be seen from the statement of the doctrine of recollection referred to above, but it can be understood from the experiment with the slave boy. In fact, I would contend that this is the point of the experiment. ${ }^{12}$

The key term in the second formulation of Meno's paradox is the verb "to know". Either one knows something or one does not know something. Given that one knows something, there is no reason to search for what one knows, because one has the object of one's inquiry. Given that one does not know, one cannot search for it because one would not recognize the object of inquiry. If there were some other epistemic state besides knowing that would allow for inquiry then the paradox would not obtain.

This, then, is what the experiment with the slave boy intends to demonstrate, namely, that belief can guide inquiry. Socrates uses a Greek speaking slave from Meno's household in the demonstration. The only requirement Socrates places on the slave boy is that he speak Greek. Also, Socrates, later in the experiment, asks Meno whether the slave boy has been taught mathematics. He has not. The slave boy answers Socrates' questions boldly, and cannot find the answer to the geometric question concerning the length of the side of the square of the double length. At line 84a, the slave boy admits that he does not know. Then, something different happens. Meno is brought back into the dialogue, and Socrates compares the condition of the slave boy now that he has admitted to Socrates that he does not know. Socrates, at line $84 \mathrm{c}$, claims that the slave boy has benefitted by being numbed and that he will come out of his perplexity while searching for the geometric answer with Socrates.

Later, in the course of the experiment, Socrates draws a square 
four times the size of the initial square, and then proceeds to draw lines that bisect each square diagonally. When Socrates asks the boy to consider how large the interior figure is, the boy still does not understand. This is important, because if we recall the advise Socrates gives Meno on how to properly define shape, at line $75 \mathrm{~d}$, the answers given must not only be true but given in terms admittedly known to the questioner. Socrates then has the boy consider the relationship between the initial square, the line that bisected the initial square, and the resulting square that is four times the initial size. The boy is able to recognize and explain these simple mathematical relationships, and then proceeds to point to the line that finally results in the square of the double size. Notice that the boy does not name this line, but merely points to it (line $85 \mathrm{~b}){ }^{13}$ Socrates names this line the diagonal (diametron). The Greek here is instructive, because diametron literally means 'a measured allowance' or 'ration'. ${ }^{4}$ The verb diametreo means 'to measure through' or 'to measure out in portions' or 'to distribute'. ${ }^{15}$ Here, the word 'diametron' is being used in the geometric sense of the diagonal. Socrates, in fact, calls attention to this when he claims that wise men (sophistai) call this the diagonal. R.W. Sharples notes that Socrates does not introduce the technical term until after the solution has been reached. The solution to Socrates initial problem does not depend on the sort of expertise involved in knowing technical terms. Sharples also notes that the term sophistai does not have to mean 'the sophists' in the technically late fifth-century sense or to have some pejorative sense in itself. ${ }^{16}$

At this point, the boy drops completely out of the dialogue. Socrates then addresses Meno, and draws out some implications to this experiment. What is revealing here is the language that Socrates uses in order to describe what has just taken place. Socrates does not claim that the boy had expressed any knowledge that was not his own, but that the boy had expressed opinions. In fact, when Socrates, at line 85c, claims that the man who does not know has within himself true opinions about things that he does not know, Socrates continues to use the term 'opinion'. Others mistaken in thinking the doctrine of recollection is offered as a theory of knowledge fail to note that all Socrates claims is that the 
boy has true opinion. This is not the same as knowledge as I will make clear below.

The remaining portion of this section of the dialogue must be interpreted carefully. At line $86 \mathrm{~b}$, Socrates makes the claim that he does not insist that his argument is right in all other respects, but that he would contend at all costs both in word and in deed as far as he could that we will be better men, braver and less idle, if we believe that one must search for the things one does not know, rather than if we believe that it is not possible to find out what we do not know and that we must not look for it. This is the retraction that I spoke of earlier in this paper. The question remains, what part of Socrates' argument does he think is not right?

My suggestion is that Socrates is uncomfortable with the latter portion of the account: namely, the portion of his argument that these opinions were pre-existing within the soul of the slave boy. The weak premise in the argument is found at line $85 \mathrm{~d}$.

These opinions have now just been stirred up like a dream, but if he were repeatedly asked these same questions in various ways, you know that in the end his knowledge about these things would be as accurate as anyone's. (Plato. Meno. line $85 \mathrm{~d}$. trans. Grube.)

One might wonder from where have these opinions been stirred? There are two possibilities from whence these opinions come. Either the slave boy has always had these opinions, and Socrates' questioning has made the boy aware of them, or these opinions were merely possible opinions opineable by the slave boy because he speaks Greek. That is, given that the boy is a competent speaker of Greek, the expression of these opinions is possible grammatical structures in the language. If we inclined to believe the stronger interpretation, that the boy has always had these opinions, then we might be led to the conclusion that these opinions were always in the soul of the boy. Socrates' questioning has only allowed the boy to become aware of them. That would imply that the doctrine of the immortality of the soul must be assumed to be true within this dialogue. Of course, this is the standard interpretation of this passage. But this interpretation does not address the reservations expressed by Socrates at the end of the expcriment with the slave boy. 
On the other hand, if we are inclined to believe the weaker interpretation, that these opinions express possible grammatical structures within the Greek language, and the boy has proven that he is a competent speaker of Greek, then the stirring up done by Socrates' questioning is the result of taking advantage of this possible grammatical structure, and expressing it. This weaker interpretation does not imply that the boy's soul contains or does not contain these opinions. On the contrary, this weaker interpretation is justified in light of the one restriction Socrates placed on the selection of the slave boy, which is, that he speak Greek. Also, this interpretation does seem to make sense in light of the passage where Socrates compares knowledge to the statues of Daedalus. At 98a, Socrates claims that true opinions, as long as they remain, are a fine thing and all they do is good, but they are not willing to remain long, and they escape from a man's mind, so that they are not worth much until one ties them down by giving an account of the reason why. Unlike opinions, knowledge remains in place. Prior to this passage, Socrates refers to a run-away slave. This allusion suggests a comparison to the passage with the only slave in the dialogue.

We do not get a clear answer in the dialogue as to what ties down knowledge. Socrates refers to the account of the reason why, and what counts as the aitiai logismoi is not discussed here. The only suggestion we find is that if the slave boy is asked these questions and others like them again and again then his knowledge of the matter will be as good as one who knows. But, this takes us far afield of the position that I am arguing for.

At this point, we might wonder whether my proposal addresses both how we acquire knowledge and the origin of knowledge. With respect to the question of how we acquire knowledge, the interrogation of opinions by means of the dialectic is the short answer. With respect to the question of the origin of knowledge, my solution is that all the dialogue warrants us to say is that propositions are the product of linguistic formations (noun and verb combinations) inherent in the home language of the inquirer. What my interpretation frees us of the need to invoke metaphysical commitments that may or may not be warranted from the dialogue. True, Plato does use language reminiscent of metaphysics 
(immortal soul, previous incarnations of the soul, ex-corporeal existence and experience of the soul). However, this language is found within the frame of the account of what priests and priestesses say about their practices. That is to say, within the metaphoricalmystical account initially offered to Meno by Socrates before he counters the paradox.

So, if this portion of the account, namely the idea that the soul contains within it all knowledge simply on account of its successive incarnations, of the doctrine of recollection does not seem to affect the experiment with the slave boy, one must wonder what role this is intended to play in the presentation of the doctrine. That is to say, is this one of the portions of the demonstration that Socrates recants at the end?

Returning to the initial presentation of the doctrine of recollection in the Meno, at lines $81 \mathrm{c} \mathrm{d}$, notice that Socrates defines learning in terms of recalling. Nothing more is said concerning the nature of this recalling or by what mechanism the recalling takes place. What we see in the experiment with the boy is that the use of dialectic is the mechanism by which the recalling happens. I draw attention to this passage again because, with the exception of the word "recollection," nothing more is made of the nature of the recalling except that we recall things from previous incarnations. ${ }^{17}$ In a very real sense, we really do not have recollection at work here.

With these problems, it seems prudent to adopt an interpretation of the doctrine of recollection in the Meno that does not commit us to such problematic metaphysical notiions. I argue that the weak interpretation does not so commit us. Yet this interpretation leaves us with a few remaining problems. First, in what way does inquiry take advantage of grammatical possibilities in a language that lead to belief formation? My suggestion is that the example of the square drawn in the sand and used by Socrates in the experiment plays a vital role here. Recall that the slave boy points to the correct line that answers Socrates' question. Socrates names this line the diagonal, but the Greek literally says that it is the line that measures the portions. I suggest that we may want, in fairness, to retranslate this as the "line that cuts in half", because this carries the notion connoted in the Greek better than the geometric term. My 
suggestion is that experience plays morc of a role here than previous interpretations might seem to suggest. This is not to say that Plato is an empirical philosopher. However, this does seem to suggest that there may be more going on with this example that Plato takes advantage of when he reformulates the doctrine of recollection in the latter dialogues. Further, this interpretation does not address the nature of the questions Socrates asks the boy that leads him to the correct answer. I am not suggesting that leading questions are the only route to knowledge. On the contrary, all I am suggesting is that this is a further problem that takes us further afield of the interpretation I am working on in this paper.

In light of the above, I reiterate that the purpose of the doctrine of recollection, as it is presented in the Meno, does not commit us to the stronger interpretation found in the later dialogues. On the contrary, I am suggesting that the use of this important doctrine in the Meno is to demonstrate how one may engage inquiry where one does not possess knowledge of the object of inquiry. As such, the experiment with the boy serves as an example of how one may inquire without possessing knowledge and only using opinion as the guide.

\section{Notes}

'Although I agree with Charles Kahn, in Plato and the Socratic Dialogues, that each dialogue is a self-contained conversation, and that it is tempting to and even beneficial to read each dialogue as a separate conversation, nevertheless we cannot ascribe to Plato a multitude of various different philosophies. Despite this agreement, I think that it is vitally important to understand the positions and arguments in each of the dialogues as self-contained. It is by attending to the differences found in the separate, but parallel, arguments that Plato's real strength lies as a thinker. Only by devoting the time to understand each dialogue in its own terms, are we ever to be in a position to make good interpretations inter-dialogically. That is to say, to discover a vantage point in order to make comparisons between these separate, yet parallel arguments. This will allow us to attend to the differences in each that lead to differing conclusions.

${ }^{2}$ David Melling, in Understanding Plato Oxford: Oxford University Press. 1987. advances this claim. 
"Gregory Vlastos, in "Anamnesis in Plato's Meno" Dialogue Vol. IV. \#2., 1965. p. 143-167 and in "Elenchus and Mathematics" in Socrates: Ironist and Moral Philosopher. Cambridge: Cambridge University Press. 1991., advances this claim.

${ }^{4}$ Gail Fine, in "Inquiry in the Meno" has argued for something like this. In her article, she argues that the theory of recollection is not a theory of innate ideas. She argues that Plato takes advantage of one of the features of the elenchus that Socrates took for granted, namely the possibility of inquiry in the absence of knowledge. Inquiry does not need an initial portion of knowledge in order to inquire into what one does not know. Belief can serve as a guide to the acquisition of knowledge. Fine and I agree on the point that the Socratic elenchus is in operation in this dialogue, and that the results found in the initial portion of the dialogue are a product of the elenctic method. She, also, does not address Socrates' retraction at the end of the experiment with the slave boy, which, I shall argue, is central to understanding this part of the dialogue.

${ }^{5}$ By the "strong" interpretation, I mean any interpretation that attempts to account for the metaphysical-mystical notions suggested in the mythic account of the pre-natal account of knowledge. By the "weak" interpretation, I mean my interpretation which does not attempt to take these things into the account of this doctrine.

${ }^{6}$ Plato. Meno. line 70a. Trans. G.M.A. Grube. modified. Hackett Publishing Company. Indianapolis: Indiana. 1976.

${ }^{7}$ Plato. Meno. line 7lb. trans. G.M.A. Grube. modified.

${ }^{8}$ This is made clear by Meno's insistence at line $86 \mathrm{~d}$, on inquiring into his initial question. Although this question is slightly modified at 86d, Meno's insistence makes it clear that he is either not patient enough to undergo the trials of a Socratic investigation, or this type of investigation is something alien to him. We do know from Socrates' initial remarks that Meno is a student of Gorgias, and that Gorgias accustomed Meno to give a bold and grand answer to any question, and that Gorgias himself was ready to answer anyone and that every question was answered. (line 70c). The idea that there may be questions for which there is no ready-made answer may be something foreign to Meno.

${ }^{9}$ Thomas Tuozzo, in "Why Are There Two Definitions of Shape in Plato's Meno" in Southwestern Philosophy Review. Vol. 19, Number 1. 2003., discusses a number of the problems associated with the definitions of shape and the definition of color.

${ }^{10}$ Plato. Meno. line 76e. Trans. G.M.A. Grube. 1 think much, in this dialogue, rests on determining what work this phrase does in Plato's texts. Unfortunately, it would be inappropriate to fully explore this issue here. 
"John E Thomas, in Musings on the Meno, has suggested that this difference is far more important that I am suggesting here. Thomas argues that in Socrates' reformulation of this paradox Socrates drops the qualifier "parapan" (rendered in the translation as "know nothing at all") and that this immediately destroys the thrust of the original puzzle. My contention is, whether we use Meno's formulation or Socrates', nevertheless we come to the same conclusion: either inquiry is superfluous or it is impossible.

${ }^{12}$ Roslyn Weiss, in Virtue in the Cave. Moral Inquiry in Plato's Meno. Oxford: Oxford University Press. 2001. p. 66, claims that what Socrates looks to the myth to provide is not an accurate account of what our souls have experienced and will experience when they are not in our current bodies, but a story that will convince Meno to live courageously pursuing inquiry, even inquiry that seems hopeless to him. What Weiss takes note of, in examining the myth, are some observations of Meno. The fact that he has some technical knowledge of Empedocles, his acquaintance with the poets and his sophistic training, all play a role in his believing and attending to the myth that Socrates tells him at this juncture in the dialogue.

${ }^{13}$ David Ross, in Plato's Theory of Ideas, 1951, makes this bold claim that the boy's discovery is purely and empirical one.

${ }^{14}$ LSJ sv.

${ }^{15}$ LSJ SV.

${ }^{16}$ R.W. Sharples. Plato: Meno. Aris \& Phillips Ltd. Teddington House, Warminster, Wiltshire, England. 1984. p. 154.

${ }^{17}$ This is one of the main reasons that I want to focus on the presentation of the doctrine of recollection in the Meno alone. If we compare this presentation with the one found in the Phaedo, (lines 73c-e). what we find is that the notion of recalling is recast. In the Phaedo, we call something recollecting when one sees or experiences one thing and thinks of another thing. The example of the lover seeing the garment of the beloved and the image of the beloved accompanies the perception of the garment is used here. Notice that this is quite different from the presentation of the doctrine of recollection found in the Meno. In Meno, all we are told is that the soul recalls previous knowledge from previous incarnations. As I have argued, the number of incarnations does not affect the process of recollection whatsoever. So this seems to call into question the nature of the need for previous incarnations in the first place. On closer inspection, when we look carefully to the presentation of this doctrine, Socrates defines learning as recollection and recollection as learning. Hence, I would contend that nothing at all hangs on the word 
"recollection" here. What Socrates intends to demonstrate with the experiment with the boy is that inquiry can be guided by opinion especially when neither of the inquirers have knowledge of the thing being inquired about.

\section{References}

Fine, Gail. "Inquiry in the Meno" reprinted in Cambridge Companion to Plato. Ed. Richard Kraut. Cambridge: Cambridge University Press, 1992.

Kahn, Charles. Plato and the Socratic Dialogue: The Philosophical Use of A Literary Form. Cambridge: Cambridge University Press, 1996.

Melling, David. Understanding Plato. Oxford: Oxford University Press, 1987.

Plato. Meno. Trans. G.M.A. Grube. Indianapolis: Hackett Publishing Co., 1976.

Ross, David. Plato's Theory of Ideas. Oxford: Clarendon Press, 1951. Sharples, R.W. Plato: Meno. Aris \& Phillips Ltd., Tedington House, Warminster, Wiltshire, England, 1984.

Thomas, John E. Musings on the Meno. The Hague: Martinus Nijhoff Classical Philosophy Library, 1980.

Tuozzo, Thomas M. "Why Are There Two Definitions of Shape in Plato's Meno?" Southwest Philosophy Review, Vol. 19. No. 1, pp. 161- 168, 2003.

Vlastos, Gregory. “Anamnesis in Plato's Meno" Dialogue, Vol. IV. \#2, pp. 143-167, 1965.

Weiss, Roslyn. Virtue in the Cave. Moral Inquiry in Plato's Meno. Oxford: Oxford University Press, 2001. 